\title{
Research on Bicycle Riding Clothes
}

\author{
Zhang Kun, Wang Yanzhen \\ College of Fashion, Shanghai University of Engineering Science, Songjiang Dstrict, Shanghai, China
}

\author{
Email address: \\ 1436855745@qq.com
}

\section{To cite this article:}

Zhang Kun, Wang Yanzhen. Research on Bicycle Riding Clothes. Science Research. Vol. 3, No. 5, 2015, pp. $252-255$.

doi: 10.11648/j.sr.20150305.13

\begin{abstract}
With people's awareness of health and environmental protection improve, and now more and more people began to choose the way of low carbon, energy saving, and free travel mode- riding. In our country, Cycling clothes, as an important equipment of riding movement which is gradually entering people's field of vision. Firstly, the paper analyzes the characteristics of the structure design of cycling clothes, then the selection of the functional fabrics, the design requirements of the pattern and the color. Finally make a prospect of the future development of riding clothes in China. which can provide reference for the latter research and enterprise production.
\end{abstract}

Keywords: Cycling Clothes, Structural Design, Functional Fabrics, Pattern, Color

\section{Preface}

In recent years, with the process of transforming the nature and creating the society, the environmental problems caused by human beings have seriously threatened human's normal life. Sustainable development, save resources, and the protection of the environment have been put on the agenda of the development of all countries. Cycling exercise has low carbon, environmental protection and free reputation, which has gradually become a fashion movement back to the historical stage. This is another progress of human civilization, and is also an important trend to solve environmental problems. While the riding clothes which is linked with the riding movement closely, with the continuous growth of the players and professional athletes, which has a potential huge market. The research and development of riding clothes is to comply with this trend, as far as possible to meet the needs of athletes.

The design and development of riding clothes need to consider many aspects of the problem, such as the rationality of the structure design of the riding clothes, consider the functional problems of the fabric, whether riding clothes is satisfy the aesthetic requirements of beautiful, fashion, personality, etc., so the researchers need to do a lot of research, experiment to continuous modification and summary. In this paper, we focus on these aspects to analysis.

\section{The Origin and Development of Riding Clothes}

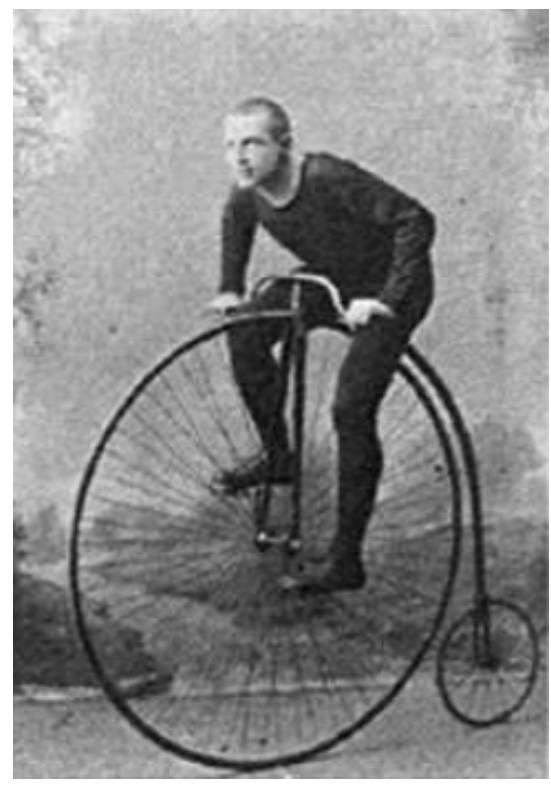

Figure 1. High front wheel bicycle.

In the western countries, there is a long history of cycling, and the riding suit is accompanied by the rise, development, change and improvement of the bicycle. As early as in 1791, the world's first "bicycle" was born, since people like to ride, so 
wear clothing is riding clothes. Afte that, the German production in 1818 can be controlled direction of two wheeled vehicles, can change the direction of the forward, the model of the bicycle began to be born. The bicycle without a chain is by increasing the diameter of the front wheel to improve the speed, so resulting the vehicle is very high, even more than the height of the ordinary people, so riding a bicycle into a dangerous sport. The rider is easy to fall and get injured(refer with: Figure 1).

In 1874 , the British people install the sprocket and chain to the bicycle, with the rear wheel to drive the rotation of the car. After more than two hundred years of development and evolution, the modern bicycle young body have been largely shaped, it is with people's demand towards the direction of diversification.

From the generation, evolution, and development of clothing, sports clothing's generated is due to the demand to the clothes of the movement. The earliest cycling clothes was designed to "Knight" clothing, Because the main means of transportation was the horse at that time, people dream of a faster traffic tool than horse, so this impression for the "horse" also as decoration in the clothing, hat, split ends of tuxedo and so on and cycling hand hold long whip. Tuxedo is upper class dress at that time, riding by wearing a tuxedo which former short, back long, back fly hem with oblique split ends. The origial purpose of Split ends is to dismount conveniently, the function of clothing that is referenced to bike riding. With the continuous improvement and development of the function of the bicycle, the bicycle is becoming a popular sport. In 1876, London held bicycle hiking rally of 2000 scale. The club members, dressed in uniforms parade, then uniform is wearing Beanies dome cap, wearing a brass buttons wool jacket, wearing platform of nicardipine Paul Katz (knickerbockers. a for man outdoors loose half pants), leg on leggings, or wear boots.

Bicycle in our country as early as appeared at the end of the 19th century, first introduced from the west to the court, as a kind of toy, then gradually become the traffic tools in the life of ordinary people, then ride wearing the clothing is gown like this. Later, due to the introduction of Western technology and culture, Western clothing material poured into the domestic market, all kinds of men and women's Western costume contests, a direct impact on the transformation of Chinese clothing and the clothing changes also reflected on the exercise bike. With the changes of the times, the past bike from a single utility function evolve the entertainment function. It is no longer just ride a bike but play, people's understanding of the bicycle is also greatly improved.

\section{Research Status of Riding Clothes}

\subsection{Domestic Research on the Riding Clothes}

Our country is still in the initial stage of the research on riding clothes. Zhao Jin from the functional point of clothing to analyze research cycling clothing design methods and ideas, and set a riding overalls as an example, analysis on the riding clothing structure design, and from riding clothing style and function of fabric selection and application, pattern, color, etc., research on the functional design requirements of riding clothes. Zhang Haihong on the road short sleeved cycling clothes has made significant improvements, and expounds the unique structural design, the sleeve of finished natural like chest thrown and inserted into the vertical state, solve the athletes wearing tight feeling. In a word, they have a discussion on the structure and material selection.Hu Xiujuan found that the existing riding clothes, comfort is not good when riding, and clothing on the body of the joints will produce friction, the use of manual measurement method to determine the size of the vertical and riding two kinds of state to determine the size of the seamless riding clothes, and complete the structure design of the seamless riding clothes. It is proposed that the seamless riding suit made of seamless knitting machine can meet the comfort requirements of riding condition. This is undoubtedly a new idea for the study of riding clothes.

\subsection{Study on the Riding Clothes of Foreign Countries}

Europe and the United States and Japan and other countries in the design and production of bicycle riding clothes technology is relatively developed, the structure design of the riding clothes and fabric application of the technology has a high technology. Foreign brands riding clothes with zipper, easy to wear off, the burden of the fine workmanship, breathable perspiration, beautiful color, the reasonable three-dimensional tailoring, pants type more stereo, annexed ergonomic, soft and breathable, comfortable next to the skin, pad uses moisture permeability of ultra light protection pad, it can completely attached to the skin and no displacement, and effectively absorb the long ride brought about by kinetic energy, lower the hips, the protective pad surface after deodorization antibacterial treatment, can rapid wicking, allowing cyclists stay dry and comfortable. Such as Nike has developed a series of new fabric can help players to adapt to cold, heat, wind, snow, rain, sweat all environment, fully embodies the raw materials, high-tech, sewing accuracy and structure design of the scientific rationality; Cool--Max developed by DuPont company of America is now the most popular cycling clothing fabric, super dehumidification, ventilation, both quick drying, anti wear, anti ultraviolet ray of a number of, but also through quickly hot flashes moisture eduction body outside temperature regulation. The experimental results show that maintain proper body temperature and activity can strengthen the muscles and alleviate fatigue.

On the current data show that the domestic in comparison with foreign of research state on riding clothes design is still not enough. In China, the research on the system of bicycle riding suit is a blank. Domestic cycling clothing production and the production of relatively backward, most grades lower, quite a part is an imitation of the international famous brand, with reference to the international big use of fabric, directly brought the results to use, and in the design, process, there is little breakthrough, choose the surface material is very low, windproof, waterproof, breathable, warm, abrasion resistance, 
tearing properties are not up to the standard of workmanship coarseness, riders are not comfortable wearing, durable.

\section{Riding Costume Design Requirements}

\subsection{Riding Posture}

Analysis of the posture of athletes can better study the riding clothes, so that more fully meet the requirements of the athletes on clothing(refer with: Figure 2). When riding, the upper body need to maintain forward, lowering the center of gravity of the body; the head slightly tilted forward, and the upper arm and body composition of angle almost at $90^{\circ}$, any bike "streamlined" can reduce wind resistance. This state, because of the bending of the arm, will consider that the shoulder sleeve will easily lead to wrinkles, but due to the back of the bend, the clothes will be stretched, and the abdomen will form a fabric accumulation, causing discomfort to athletes. Related data research shows that on the riding condition, the riding clothing of the shoulder horizontal direction elongation by $30 \%$, vertical direction elongation by $26 \%$; back clothing horizontal direction elongation by $16 \%$, vertical direction elongation by $8 \%$; hip horizontal direction elongation by $15 \%$, vertical direction elongation by $36 \%$; riding pants thigh front piece horizontal direction elongation by $40 \%$, vertical direction elongation by $37 \%$ : knee position horizontal direction elongation by $30 \%$, vertical direction elongation by $42 \%$. Therefore, the special position of the riding decided the key points in the design of the structure and the choice of fabric.

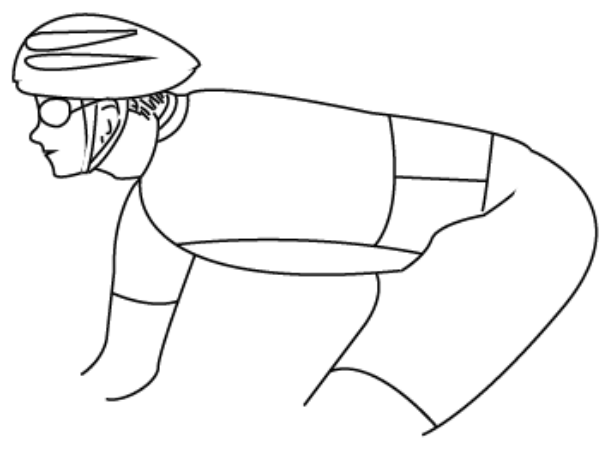

Figure 2. Riding posture.

\subsection{Riding Clothes Design Key Points}

\subsubsection{Structure Design Features}

According to the above analysis of the riding posture, the body can not be in accordance with the normal state of the human body in a vertical structure design, which need to use a combination of three-dimensional cutting and plane cutting and need patiently and repeatedly test and correction. First of all, it is of hip length with a drop back hem (longer in the rear), which is to minimize the accumulation of fabric in the abdomen, to pay attention to minimize the design of the split line, to reduce the friction between the joints of the body. Secondly, the coat hem, cuff and trousers need to install anti-skid belt, which is to prevent the movement of these parts of the fabric to slip. Thirdly, the shoulder sleeve of the riding suit is generally used in the structure design of raglan sleeve and cape sleeve and drop-shoulder sleeve. The purpose is to increase the movement range of the shoulder and facilitate the movement. In addition, front fly usually adopts the zipper design, on the one hand is to wear off easily, on the other hand is to reduce when riding the wind resistance.

\subsubsection{Selection of Functional Fabrics}

Functional fabric is a kind of fabric with some special properties, special function, mainly through the high-tech and finishing. The choice of functional fabric will directly affect the final result of the garment, so it is very important to select the fabric. Riding clothes fabric performance: the fabric can absorb intense exercise discharge sweat, with appropriate water permeability and air permeability, so as to avoid the occurrence of thermal and humid caused by sweating; in the summer or hot weather, which has anti radiation and anti ultraviolet radiation damage performance. In the winter or cold weather, the fabric can have a good against the cold, windproof, waterproof performance; a reflective and luminous performance, in night driving which can make the athlete visible and avoid the occurrence of accident; soft and lightweight performance, which can reduce the sense of oppression to the athlete; stain resistant to sunlight, water washing resistance, and resistance to soaping fastness performance.

At present the research and development of Jersey, which is usually used in polyester and Lycra blend fabric; the riding trousers often use COOl-MAX fabric which is made by the Du Pont company and it can rapidly absorb hot flashes moisture to exclude in vitroin to regulate body temperature.

\subsubsection{Design Requirements of Pattern and Color}

In addition to consider the structural design, the selection of functional fabrics, and do not ignore the pattern, the color. With the improvement of people's aesthetic consciousness, the modern people's demand for sports clothing is not limited to only meet the basic functions of sports clothing, and more tend to the aesthetic, personality, fashion. The distinctive color combination and personalized patterns can be very eye-catching to bring you a very intuitive feeling. So riding clothes design need to pay attention to the combination of fashion and sports fashion, as well as the combination of pattern, color and brand spirit. In short, the color pattern of the riding clothes requires coordination with the body size, team unity, beautiful fashion and other characteristics.

The pattern design is a prominent bright spot in the movement clothing, because the pattern may display the individuality and thought expression. Common design elements of the design elements, such as the brand logo, interesting cartoon, painting, pictures, etc. Awake and stimulating color structure is easier to identify and memory, which can give the referee and the audience a deep impression. The pattern design of riding clothes is simple, crisp, generous and eye-catching. The Jersey pattern mainly is designed by the computer design, the embroidery and stamping process.

Clothing color in the process of people's visual perception 
can have the fastest information, the deepest emotional expression, the biggest the impact of the visual sense, the most aesthetic appeal, and the deepest impact of human mental and emotional. Fixed color collocation combination can improve the color memory of clothing, which will give people a color of memory. If it win the audience's color memory, it is the basis of winning team image. The colors of the riding clothing are blue, white, red and black, and which are often used in a suit of contrasting colors or complementary colors. This is a feature of modern riding clothes.

Jersey color pattern fabric is a superb collection of beautiful things for processing or processing by weaving printing and dyeing. But the majority of the whole ride adopt thermal transfer printing technology, which is printed on the pattern of riding clothes and the merchant's logo. The thermal transfer printing pattern has the characteristics of flower pattern, fine pattern, clear level and strong stereo feeling.

\section{Riding Clothes in the Future Development of China}

Riding sports has developed in full swing in the European and American developed countries because of fashion, green environmental protection, but has just started in China. However, in the past 3 years, the data show that the rapid development of the market from 2010 to 2013, and the total domestic market has grown from ten million yuan to one hundred million yuan. Some of the local traditional outdoor brand on the sport, which is interested in it and begin to integrate resources and expand the category of riding products in order to the ride clothing market blowout.

With people's pursuit of the sports clothing personalized, and aesthetic and fashion demand is more and more outstanding. The guidance of human nature of the design will also lead the direction of the design of fashion, protection of professional, process oriented development. For riding clothing materials in China, the research and development of new fabrics, design and processing technology has not reached the international advanced level. And some well-known domestic brands for the production of sports clothing, have the choice of importing materials so that Chinese should improve the domestic research and innovation capabilities and technical level, and enhance the development of domestic fabric enterprises, and enhance the competitiveness of China's high-tech fabrics in the international sports service market, which has important significance.

\section{Conclusion}

With the integration of world economy and the rapid development of China's sports industry, China's sports apparel market is facing unprecedented opportunities and challenges. The development of riding suit in China is still in its initial stage. The design, production process and application of the fabric are also obviously insufficient compared with the developed countries in Europe and America. In the face of the huge demand market in China, the academic research on the theory of the riding suit is becoming more and more important, and more and more scholars need to be involved in the research. And domestic production enterprises in China should be updated from the equipment, fabric development, design, color, reasonable use of collocation and the use of advanced production technology and other aspects of the product development, so that the abilities of riding clothes can reach even more than foreign standards.

\section{Acknowledgement}

The paper is founded by the Shanghai university of Engineering project. The project number is E1-0903-15-01081,and its title is 15KY0904.

\section{References}

[1] Feng Zeming, Liu Haiqing. Development of Chinese and Western clothing [M]. Beijing: China Textile Press, 2005:140.

[2] Zhao Jin. Functional apparel design and research[J]. textile industry and technology.2011 (2).

[3] Zhang Haihong. Development of a new type of riding jacket [J]. knitting industry, 2006 (2).

[4] Hu Xiujuan, Yan jade show Chen Huiji. Seamless apparel, structure design of [J].2010 Journal of Zhejiang Sci-Tech University (1).

[5] Zhao Jin. The design and production of bicycle riding suit [D]. Soochow University. Research student.2009.

[6] Hu Xiujuan. The structure design and research of seamless riding service with wind resistance [D].2009.

[7] Dong Shuting. Non competitive cycling apparel design [D]. master degree thesis.2012.

[8] Qing Feng. The potential of a huge riding equipment market attention 2014 Shanghai international outdoor cycling equipment exhibition [J]. China bicycle, 2014 (3). 